\title{
Atomoxetine for the treatment of attention-deficit/ hyperactivity disorder in children and adolescents: a review
}

\author{
Paul Hammerness \\ Katherine McCarthy \\ Elizabeth Mancuso \\ Cassandra Gendron \\ Daniel Geller \\ Clinical and Research Program \\ in Pediatric Psychopharmacology, \\ Massachusetts General Hospital \\ and Harvard Medical School, \\ Cambridge, MA, USA
}

\begin{abstract}
Objective: This review examines and summarizes the pharmacodynamic and pharmacokinetic properties, short- and longer-term efficacy, the moderating effect of comorbid disorders, as well as short- and long-term safety and tolerability of atomoxetine for the treatment of pediatric attention-deficit/hyperactivity disorder (ADHD).

Methods: A systematic literature search was performed to review the extant literature on articles pertaining to the pharmacological treatment with atomoxetine in pediatric and/or adolescent ADHD.

Results: There is an extensive literature on atomoxetine; over 4000 children have participated in clinical trials of atomoxetine, demonstrating its short- and longer-term efficacy. In addition, studies have examined the moderating effect of comorbid disorders on atomoxetine response, as well as atomoxetine's therapeutic potential for other psychiatric conditions. Short- and longerterm safety and tolerability continue to be reported.

Conclusions: Atomoxetine is indicated for both acute and maintenance/extended treatment of pediatric ADHD. Clinicians and families must be familiar with atomoxetine's evidence base, including its profile of clinical response and its possible effectiveness in the presence of comorbidity.

Keywords: ADHD, atomoxetine, pediatric
\end{abstract}

\section{Introduction}

Attention-deficit/hyperactivity disorder (ADHD) is the most common childhood neurobehavioral disorder in the United States with an estimated prevalence of $6 \%$ to $8 \%$. ${ }^{1}$ Both the American Academy of Pediatrics (AAP) and the American Academy of Child and Adolescent Psychiatry (AACAP) recommend either a stimulant or atomoxetine as psychopharmacological agents for its treatment. ${ }^{2,3}$ Atomoxetine (Strattera ${ }^{\circledR}$; Eli Lilly and Company), a selective norepinephrine reuptake inhibitor (SNRI), is the only non-stimulant approved by the FDA for the treatment of ADHD in children, adolescents and adults. While stimulant class medications are frequently used as first-line agents, atomoxetine may also be considered as an initial choice, particularly in the presence of select comorbid disorders, including active substance abuse, anxiety disorder or tic disorder. ${ }^{2}$

Here we aim to summarize the extensive literature on atomoxetine, including its pharmacodynamic and pharmacokinetic properties, short- and longer-term efficacy, the moderating effect of comorbid disorders, as well as short- and long-term safety and tolerability. We will close with summary clinical recommendations for the use of atomoxetine in pediatric ADHD.

\section{Pharmacodynamics}

Atomoxetine is a potent norepinephrine (NE) uptake inhibitor in vitro and in vivo with relatively low affinity for 5-HT and DA uptake sites; ${ }^{4,5}$ it has 290 -fold lower 
affinity for dopamine transporters than norepinephrine. ${ }^{6}$ Mechanistically, inhibition of the NE transporter blocks synaptic clearance of NE, thereby increasing synaptic NE concentrations in noradrenergic pathways. For example, $\mathrm{NE}$ in prefrontal cortical (PFC) regions has been shown to play a key role in attention and higher cognitive processes. $^{6}$

In animal studies, atomoxetine has been shown to selectively increase dopamine (DA) to a similar magnitude as $\mathrm{NE}$ in the PFC, due to region-specific shared monoamine uptake inhibition, while not altering DA in other dopaminerich brain regions such as nucleus accumbens and striatum. ${ }^{6}$ In addition, atomoxetine robustly increased NE in other brain regions with a substantial density of norepinephrine transporters; atomoxetine rapidly and persistently increased norepinephrine in rat occipital cortex, lateral hypothalamus, dorsal hippocampus, and cerebellum. ${ }^{7}$

\section{Pharmacokinetics}

\section{Absorption and distribution}

Atomoxetine is efficiently absorbed after oral administration (range 63\%-94\%); its bioavailability is minimally affected by food. After oral administration, atomoxetine reaches a maximum plasma concentration in approximately 1 to 2 hours. Atomoxetine is highly protein bound, roughly $98 \%$, specifically to albumin. ${ }^{8-10}$

\section{Metabolism and elimination}

There are three metabolic pathways involved in the clearance of atomoxetine; aromatic ring-hydroxylation, benzylic hydroxylation, and N-demethylation. The hepatic enzyme cytochrome P450 2D6 (CYP2D6) is the primary metabolic pathway for atomoxetine, yielding its primary oxidative metabolite 4-hydroxyatomoxetine. ${ }^{9,11}$ Over $80 \%$ of the atomoxetine dose is excreted primarily as 4-hydroxyatomoxetine-O-glucuronide in the urine, with a minority excreted in the feces. ${ }^{12}$ It is well known that there are distinct differences within populations of CYP2D6 activity (extensive versus poor metabolizers), and that genetic tests are presently available to identify this variability. Those persons who are deemed "poor metabolizers" (PM) of CYP2D6 drugs (about 7\% of the Caucasian population) have been shown to have mean peak atomoxetine concentrations up to 5-fold higher and total plasma exposure of atomoxetine 10-fold higher than persons who have extensive (normal) metabolic (EM) activity. ${ }^{13}$ Atomoxetine has a plasma half-life of about 5.2 hours in extensive metabolizers, ${ }^{9,12}$ compared to 22 hours in poor metabolizers, as atomoxetine is metabolized through several alternative CYP pathways. ${ }^{13}$ From a clinical standpoint, the important question is: what is the practical impact of CYP metabolism status on the treatment of a given patient? A recent pooled analysis addressed this question by examining the relationship between CYP2D6 status and clinical response in children and adolescents with ADHD. ${ }^{13}$ Efficacy data were derived from 6 acute clinical trials $(\mathrm{N}=559 \mathrm{EMs}$, $30 \mathrm{PMs}$ ), while safety and tolerability data was assessed using a pooled database from 14 studies ( $\mathrm{N}=3017 \mathrm{EMs}, 237 \mathrm{PMs})$. Efficacy analyses demonstrated significantly greater improvements in ADHD rating scale scores and rates of response in PMs as compared to EMs ( $80 \%$ and 59\% response rates in PMs and EMs respectively). However, the pooled efficacy and PK data found a low (0.179) correlation coefficient between response and peak concentration; the differential efficacy between EMs and PMs may instead be related to total plasma atomoxetine exposure or area under the curve (AUC). ${ }^{13}$ In this same analysis, reduced appetite, insomnia and tremor were seen in significantly greater rates in PMs, compared to EMs. ${ }^{13}$ In addition, significantly greater increases in mean pulse rate at endpoint $(+3.9 \mathrm{bpm})$ and in mean diastolic blood pressure (DBP) at endpoint $(+1.6 \mathrm{mmHg})$ were observed in PMs, as compared to EMs. ${ }^{13}$ The authors suggest that these differences may be due to increased noradrenergic tone in PM and/or due to persistent effects due to more constant drug concentrations throughout the day.

Since atomoxetine is highly protein bound, systemic clearance of atomoxetine may be significantly reduced in those patients with hepatic impairment. Dosage adjustment is recommended in these patients. ${ }^{14}$

\section{Efficacy Short-term atomoxetine treatment in children and adolescents}

Pivotal studies of atomoxetine in pediatric ADHD first emerged in 2001. Following a small open-label dose ranging study, ${ }^{15}$ a large randomized controlled trial demonstrated superior efficacy of $1.2 \mathrm{mg} / \mathrm{kg} /$ day and $1.8 \mathrm{mg} / \mathrm{kg} /$ day doses compared with placebo. ${ }^{16}$ This multicenter 8 -week trial included 297 children and adolescents with ADHD. All subjects began with $0.5 \mathrm{mg} / \mathrm{kg} / \mathrm{day}$, in divided (twice daily) dosing, increased at weekly intervals. Efficacy was measured using parent and investigator ADHD rating scales; the $1.2 \mathrm{mg} / \mathrm{kg}$ and $1.8 \mathrm{mg} / \mathrm{kg}$ doses were significantly superior to placebo at reducing ADHD symptoms, with similar improvement for inattentive and hyperactive/impulsive subtype symptoms. Improvements in social and family functioning were also observed using a number of secondary outcome measures. 
The magnitude of improvement with atomoxetine treatment as judged by teachers has been found to be similar (effect size $=0.63)$ to that seen in studies based on investigator interviews with parents $(0.6$ and 0.8$) .{ }^{17}$ This study, by Weiss et $\mathrm{al}^{17}$ used the ADHD-RS-IV-Teacher:Inv as the primary outcome measure. This scale was completed by investigators during a 4-day period before each study visit, based on a telephone interview with the child's primary teacher. Teachers reported improvement within 1 week of initiating therapy.

Overall, short-term ADHD symptom improvement has been demonstrated in multiple settings as assessed by clinician, parent, and teachers, and as measured according to a variety of outcomes over the short term. A recent meta-analysis reported the number-needed-to-treat (NNT) for atomoxetine treatment response (reduction of $\geq 25 \%$ in ADHD-RS total score from baseline) was 3.43 (95\% CI, 2.79-4.45). ${ }^{18}$ Significant improvement compared with those treated with placebo has been demonstrated across efficacy measures, in younger (6-7 years) and older (8-12 years) children: ADHD-RS total score: younger $\mathrm{ES}=0.77$, older $\mathrm{ES}=0.65$; Inattentive subscale: younger $\mathrm{ES}=0.71$, older $\mathrm{ES}=0.59$; Hyperactive/Impulsive subscale: younger $\mathrm{ES}=0.76$, older $\mathrm{ES}=0.62$; CGI-ADHD-S score: younger $\mathrm{ES}=0.62$, older $\mathrm{ES}=0.59 .{ }^{19}$ However, overall in the treatment of pediatric ADHD, superior effect sizes are consistently observed with immediate-release and long-acting stimulants, as compared to non-stimulants, including atomoxetine. ${ }^{20}$

\section{When does clinical response occur?}

The full efficacy of atomoxetine may not be seen in short-term treatment studies. In two very short-term (3-week) open-label studies with OROS methylphenidate ${ }^{21}$ and mixed amphetamine salts extended release (MAS XR) comparators, ${ }^{22}$ each stimulant medication demonstrated superior effectiveness over atomoxetine, while a 10-week study by Kratochvil et $\mathrm{al}^{23}$ reported similar effectiveness with either atomoxetine or immediate-release methylphenidate. A gradual clinical response to atomoxetine is depicted in the report by Wilens et al; in a large sample $(\mathrm{N}=882)$ of adolescents, mean ADHD-RS score continued to decline up until the 3rd month of treatment, at which point scores stabilized and remained so, over 24 months of treatment. ${ }^{24}$ Thus, patience with this medication may be necessary in order to appreciate its full efficacy.

\section{Does dosing matter?}

In theory, twice daily dosing may provide greater efficacy with more consistent plasma atomoxetine exposure, consistent with PK findings. ${ }^{13}$ However, several trials have demonstrated that atomoxetine appears to be as effective when the dose is given as a single daily dose. ${ }^{17,25,26}$ In the latter study, ${ }^{26}$ which used a more rapid early dose titration schedule, statistically significant improvement was observed after 1 week of treatment, with evidence for superior efficacy, compared with placebo, as soon as the first day of treatment, according to daily analyses of parent ratings.

For example, Kelsey et $\mathrm{al}^{26}$ reported on a large group of children receiving 8 weeks of once daily atomoxetine or placebo. Atomoxetine titration was relatively rapid, beginning at $0.8 \mathrm{mg} / \mathrm{kg} /$ day for 3 days, increasing to $1.2 \mathrm{mg} / \mathrm{kg} /$ day for 4 weeks, with the option to increase to $1.8 \mathrm{mg} / \mathrm{kg} /$ day according to tolerability and clinical assessment. Using a novel instrument, parents rated children's behaviors in the morning (before AM dosing and representing trough levels) and evening (after 6 PM), such as getting up, doing homework, and sitting through dinner. Parents recorded observations using an electronic entry system to record on a daily diary. Total score, as well as evening and morning subscales showed statistically significant improvements from baseline to endpoint. Comparisons of mean changes in individual parent ratings demonstrated significant atomoxetine-specific reductions for 5 of 8 evening items and 2 of the 3 morning items. Results obtained with a validated scale assessing evening behaviors (Conners' GIPE) also showed statistically significant improvements in total score for evening behaviors from baseline to endpoint. The treatment effect size in this study for the primary outcome measure was 0.7 , compared with $0.8,0.7$, and 0.6 in the studies of twice-daily atomoxetine. ${ }^{26}$

\section{What about atomoxetine response in children previously treated with stimulants?}

In a unique crossover design, Newcorn et $\mathrm{al}^{27}$ reported on the response to atomoxetine in children who had been previously treated with stimulant medication. Youth with ADHD, any subtype, were randomly assigned to receive 0.8 to $1.8 \mathrm{mg} / \mathrm{kg} / \mathrm{day}$ of atomoxetine ( $\mathrm{N}=222), 18$ to $54 \mathrm{mg} /$ day of OROS MPH $(\mathrm{N}=220)$, or placebo $(\mathrm{N}=74)$ for 6 weeks. For youth with a history of stimulant treatment $(\mathrm{N}=301)$, the response rate for atomoxetine was $37 \%$, as compared to the $57 \%$ response rate observed in patients who were stimulant naive at study entry $(\mathrm{N}=191)$. Meta-analysis demonstrating the short-term efficacy of atomoxetine in children and adolescents includes high rates of children (57\%) and adolescents (75\%) with prior stimulant exposure. ${ }^{24}$ 


\section{Special populations: children with poor prior stimulant response}

The Newcorn et $\mathrm{al}^{27}$ trial is the only large, controlled study to offer within-subject data (crossover) characterizing treatment response to atomoxetine in children who did not respond to stimulant treatment during the study itself ( $\geq 40 \%$ decrease in ADHD rating scale). After 6 weeks of initial treatment, under double blinded conditions, children treated with OROS MPH were switched to atomoxetine. For the 70 youths who did not respond to OROS MPH in the trial, $43 \%$ subsequently responded to atomoxetine.

Overall, despite limitations noted by the authors (eg, no washout period between the two treatments), there are helpful clinical findings in this novel study. About one-half of subjects who switched to atomoxetine after completing 6 weeks of methylphenidate responded robustly to both treatments. Yet, the majority of the others responded preferentially to one treatment, either methylphenidate or atomoxetine. A sizeable smaller number (22\%) were non-responders to both methylphenidate and atomoxetine. Differential response may be due to pharmacologic, metabolic and pharmacokinetic differences at an individual level.

There are two previous studies in which children were a priori selected for atomoxetine treatment based upon incomplete response or intolerance to prior stimulant treatment. ${ }^{28,29}$ In the Quintana et $\mathrm{al}^{28}$ study, significant mean reductions in ADHD-RS Parent:Inv total scores were observed from baseline to end point ( 32.1 vs 22.6 ; $<<0.001$ ). However, this study was limited by a stepwise cross titration, with ongoing stimulant treatment during the first 2 weeks of atomoxetine treatment.

Hammerness et $\mathrm{al}^{29}$ conducted a prospective short-term, open-label study of atomoxetine in the treatment of youth with ADHD who had been non-responsive and/or had a history of poor stimulant tolerability. In this study, atomoxetine monotherapy (doses of up to $1.4 \mathrm{mg} / \mathrm{kg} /$ day) was associated with significant reductions in ADHD symptomatology and significant overall global improvement (CGI-I ADHD). The magnitude of response to atomoxetine (53\% with $30 \%$ reduction in ADHD-RS; $41 \%$ with 50\% reduction) was consistent with previous controlled clinical trials of atomoxetine in pediatric ADHD. ${ }^{16}$

\section{Special populations: young children}

Kratochivil et al ${ }^{30}$ recently reported on the safety and effectiveness of atomoxetine in an open-label study with 22 subjects, ages 5 to 6 . The mean final dose was $1.25 \mathrm{mg} / \mathrm{kg} /$ day. Comparable efficacy to older age groups was observed, with a mean decrease of 21 ADHD-IV RS total points $(\mathrm{SD}=12.8$, $\mathrm{p}<0.001)$. Similar mean decreases of 10 points $(\mathrm{SD}=7.48$, $\mathrm{p}<0.001)$ on the inattentive subscale, and 11 points $(\mathrm{SD}=7.04, \mathrm{p}<0.001)$ on the hyperactive/impulsive subscale were reported.

\section{Can atomoxetine be combined with stimulants?}

Due to the presence of residual ADHD symptoms following primary treatment, adverse effects or psychiatric comorbidity, clinicians commonly utilize a combination of medications for youth with ADHD. ${ }^{31}$ Two recent studies examined the combination treatment of atomoxetine and stimulant. ${ }^{32,33}$ Carlson et $\mathrm{al}^{32}$ took a small group of children who did not initially respond to 4 weeks of atomoxetine and randomized them to atomoxetine + OROS MPH $(\mathrm{N}=9)$ or atomoxetine + placebo $(\mathrm{N}=12)$ for an additional 6 weeks. There were no significant differences between groups; however the small sample size and the use of subjects who were resistant to previous stimulant trials and retested on MPH limits the finding.

Wilens et $\mathrm{al}^{33}$ conducted a similar design, 2-phase, 7 -week open study in children aged 6 to 17 years. However, children were not selected based upon prior lack of response to stimulant treatment. After monotherapy with atomoxetine for 4 weeks, partial responders to atomoxetine added OROS MPH (titrated to $54 \mathrm{mg}$ over a subsequent 3 weeks) to their regimen. Subjects were assessed on multiple outcomes including ADHD, executive functioning and adverse effects. Of fifty subjects treated with the combination therapy, 41 subjects completed the entire protocol. There was a $40 \%$ reduction in their ADHD-RS from the beginning of combination treatment through the end of study (from 21.14 \pm 9.9 to $12.8 \pm 9.7, \mathrm{t}=6.5, \mathrm{p}<0.0001$ ). In addition, there was a clinically significant reduction in the Clinical Global Index of ADHD severity from moderate to mild ADHD as well as improvements in executive functioning. ${ }^{33}$ Hammerness et $\mathrm{a}^{29}$ reported the tolerability of this combined regimen; compared to atomoxetine alone, adjunct OROS MPH was associated with significantly greater rates of insomnia, irritability, and loss of appetite.

\section{Longer-term atomoxetine: is efficacy maintained?}

The benefit of maintaining pediatric patients (ages 6-15 years) with ADHD on atomoxetine has been demonstrated in controlled studies, allowing for atomoxetine to receive the unique indication for both acute and maintenance/extended treatment 
of ADHD. However, according to current prescribing information, the long-term usefulness of atomoxetine for an individual patient should periodically be re-evaluated over extended treatment periods (Lilly, Product Information, Sept 2008).

In recent meta-analyses of controlled and open-label studies, the maintenance of efficacy (according to ADHD-RS-IVParent:lnv) is demonstrated over 2 years; $25.7 \%$ of children, ${ }^{34}$ and $16.5 \%$ of adolescents discontinued due to lack of effectiveness over the study period. ${ }^{24}$ Similarly, in the Spencer et al ${ }^{35}$ report documenting safety of 5-year maintenance, only $16 \%$ discontinued due to lack of efficacy.

Atomoxetine maintenance has also been studied in children and adolescents in a naturalistic setting. A recent observational open-label study of patients $(\mathrm{N}=627$; mean age $=11$ years) with $\mathrm{ADHD}$ involved children treated at 60 physicians' offices across the United States and Puerto Rico. ${ }^{36}$ Physicians were prescribed atomoxetine either as initial treatment or after trying another ADHD treatment (eg, stimulants, antidepressants). Atomoxetine administration, dosing, and timing of follow-up visits occurred at each physician's discretion. Treatment length ranged from 0 to 89 weeks with an average span of 21.2 weeks. The primary measure of efficacy was the Physician Global Impression: ADHD Severity (PGI-ADHD-S) scale, which had a mean severity decrease of 0.91 (95\% CI: -1.00 to $-0.82, \mathrm{p}<0.001)$. Fifty-nine to $69 \%$ of subjects demonstrated consistent control of ADHD symptoms throughout the day, with improvement in subjects' grades reported by teachers, and improvement in subjects' behavior reported by parents.

\section{Is there evidence of relapse}

\section{after atomoxetine is stopped?}

A unique study by Michelson et $\mathrm{al}^{37}$ examined relapse in a large pediatric sample derived from 33 academic investigative centers in Europe, Israel, South Africa, and Australia. The study included children and adolescents who had previously participated in a 12-week open-label atomoxetine treatment. ${ }^{38}$ Of the original 416 subjects, 163 (26\%) completed 1 year of treatment with atomoxetine and were re-randomized to 6 additional months of treatment with atomoxetine $(n=81)$ or placebo $(n=82)$. Subject worsening of symptoms (defined as symptom severity returning to $50 \%$ of baseline) was significantly greater in those switched to placebo (47.6\%), than those who remained on atomoxetine (28.4\%). Buitelaar et al's ${ }^{39}$ report extends these results; after 1 year, $42 \%$ of those in the placebo group would be classified as relapsers (increase in ADHD-RS total score to $\geq 1.5$ standard deviations above norm) compared with $22 \%$ of atomoxetine-treated subjects $(\mathrm{p}=0.010)$.

\section{Efficacy - comorbid conditions}

Up to $60 \%$ of children with ADHD suffer from psychiatric comorbidity, including oppositional defiant disorder (ODD), anxiety and mood disorders, tic disorders, and pervasive development disorder (PDD).

\section{Oppositional defiant disorder}

The most common co-morbid condition of ADHD is ODD, which occurs in $40 \%$ to $60 \%$ of children with ADHD. ${ }^{40}$ However, the methodology and patient population selected to study atomoxetine response in ODD has varied considerably. The recent meta-analysis on this topic ${ }^{40}$ identifies some of these limitations; differences in inclusion criteria eg, subject ages (inclusion or exclusion of adolescents), study duration $(6,7$, or 8 weeks of exposure), diagnostic entry criteria (1.0 vs 1.5 standard deviations above the norm).

\section{Does atomoxetine work in children with ADHD and ODD/ODD symptoms?}

In a recent report, Biederman et $\mathrm{al}^{40}$ examined whether comorbid ODD impacted response to atomoxetine in children with ADHD. Acute-phase data were analyzed from three randomized, double-blind, placebo-controlled studies in children aged 6 to 16 with ADHD conducted in the USA and Canada. ${ }^{17,25,26}$ Subjects received placebo or atomoxetine (max $1.8 \mathrm{mg} / \mathrm{kg} /$ day) for 6 to 8 weeks. In this large sample, $158 / 512$ were diagnosed with comorbid ODD. Relative to placebo, atomoxetine treatment significantly reduced ADHD symptoms in both ODD-comorbid and non-comorbid subjects, indicating that the presence of comorbid ODD did not affect ADHD treatment response. ADHD subjects also showed significant improvements from baseline on most of the psychosocial measures of the child health questionnaire regardless of the comorbidity with ODD.

Other reports have found greater efficacy in treating comorbid ADHD + ODD at higher dosing; in the Newcorn et $\mathrm{al}^{41}$ study, the comorbid group showed improvement compared with placebo at $1.8 \mathrm{mg} / \mathrm{kg} /$ day but not $1.2 \mathrm{mg} / \mathrm{kg} /$ day. However, Newcorn et al's ${ }^{41}$ findings have not been found by others. ${ }^{40}$

In one longer-term study, Hazell et $\mathrm{al}^{42}$ examined the influence of comorbid ODD on the relative risk (RR) of relapse during 9 months of treatment with atomoxetine for ADHD; fewer youth with comorbid ODD relapsed during maintenance atomoxetine treatment, as compared 
to youth without comorbid ODD (17\% vs $26 \%$; RR 0.67 , 95\% CI 0.42-1.06).

\section{Is atomoxetine effective in reducing ODD symptoms?}

In examinations of data from positive randomized clinical trials of atomoxetine in pediatric ADHD, ${ }^{43}$ investigators have not observed significant decreases in ODD rating scale scores in atomoxetine treated children compared to placebo; CPRS-R:S Oppositional subscore. ${ }^{44}$ Consistent with this analysis, Biederman et $\mathrm{al}^{40}$ found no significant treatment difference in the CPRS-R:S oppositional subscale change scores; reduction in ODD symptoms was highly related to the magnitude of ADHD response. One study which demonstrated statistically significant improvement in ODD may have benefited from twice-daily dosing, allowing for better control of oppositional symptoms during the evening hours. ${ }^{41}$ A recent placebo controlled trial of ADHD and ODD found significant improvement for ADHD symptoms but not for ODD symptoms at endpoint analysis. ${ }^{45}$ In this study, the investigator-rated Swanson, Nolan, and Pelham Rating Scale-Revised (SNAP-R) was used to determine treatment effect on ODD and ADHD symptoms.

\section{Pervasive developmental disorders}

Several small, short-term studies have examined the efficacy and tolerability of atomoxetine in children with PDD and ADHD symptoms. One trial with a crossover design examined atomoxetine and placebo response during 6 week periods, separated by a one week washout. ${ }^{46}$ Twelve boys and 4 girls ( 7 with autistic disorder, 1 Asperger's, 8 pervasive developmental disorder not otherwise specified) all completed at least 3 weeks of each treatment condition. On the primary outcome, the Hyperactivity subscale of the Aberrant Behavior Checklist, atomoxetine was superior to placebo $(p=0.043$, effect size $d=0.90)$. In this study, atomoxetine demonstrated significant efficacy in reducing core DSM-IV ADHD hyperactive/impulsive symptoms $(\mathrm{p}=0.005, \mathrm{~d}=1.27)$, but not inattentive symptoms $(\mathrm{p}=0.053, \mathrm{~d}=0.89)$. While atomoxetine was generally well tolerated, with no tendency to stereotypy, one participant was re-hospitalized for recurrent violence on atomoxetine. Similar effectiveness in aberrant behavior (hyperactivity subscale only) has been observed in a longer (10 week) trial, although still based upon an open trial with a small sample. ${ }^{47}$ Improvements have also been reported in irritability, social withdrawal, stereotypy, and repetitive speech. ${ }^{48}$

Tolerability may be an area to watch in this patient population; in one study, 5 patients ( $42 \%$ ) discontinued because of side effects, including gastrointestinal symptoms, irritability, sleep problems, and fatigue. ${ }^{47}$ Although again, conclusions based on these findings cannot be made due to the very small sample size.

\section{Tic disorders}

Given that stimulant medications have been associated with the onset or exacerbation of a tic disorder, atomoxetine may offer unique efficacy and/or tolerability in children with ADHD and comorbid tic disorders; Tourette's syndrome (TS), and/or simple motor tic disorder. In the largest study to date, Allen et al ${ }^{49}$ examined children (7-17 years) with ADHD and concurrent TS or chronic motor tic disorder in a double-blind randomized treatment study with placebo ( $\mathrm{n}=72$ ) or atomoxetine $(0.5-1.5 \mathrm{mg} / \mathrm{kg} / \mathrm{day}, \mathrm{n}=76)$ for up to 18 weeks. Atomoxetine was associated with a greater reduction of tic severity at endpoint relative to placebo on the Clinical Global Impressions (CGI) tic/neurologic severity scale score $(-0.7 \pm 1.2$ vs $-0.1 \pm 1.0, p=0.002)$; however significance was not reached in Yale Global Tic Severity Scale (YGTSS) total score, nor the Tic Symptom Self-Report total score. In a subset of this study that included only children with comorbid TS, atomoxetine was associated with significant reduction of tic severity on two of three measures. ${ }^{35}$

\section{Childhood anxiety disorders}

In addition to comorbid ODD and tics, approximately one third of children with ADHD have comorbid anxiety disorders. The one large controlled study of ADHD and comorbid anxiety was published this past year. In this trial, Geller et $\mathrm{al}^{50}$ enrolled 176 children (ages 8-17 years) who met DSM-IV criteria for ADHD and generalized anxiety disorder, separation anxiety disorder, and/or social phobia. Children were randomized to 12 weeks of atomoxetine $(n=87)$ or placebo $(n=89)$. Sixty-six patients in each group completed the study. Mean ADHD-RS-IV-Parent: Inv total score improved significantly for atomoxetine $(\mathrm{n}=55 ;-10.5, \mathrm{SD} 10.6)$ relative to placebo $(\mathrm{n}=58 ;-1.4$, SD 8.3; $<<0.001 ; \mathrm{ES}=0.84)$. Mean Pediatric Anxiety Rating Scale (PARS) total score also improved significantly for atomoxetine ( $\mathrm{n}=55 ;-5.5, \mathrm{SD} 4.8)$ relative to placebo $(\mathrm{n}=58 ;-3.2$, SD 5.0; $\mathrm{p}=0.011)$. There was also a significant reduction in independently assessed anxiety symptoms using both clinician-rated and self-rated measures.

In comparison, a study by Abikoff et $\mathrm{al}^{51}$ involved the sequential treatment of children with ADHD and anxiety using fluvoxamine. While children with ADHD and anxiety 
were found to have a response rate to stimulants for ADHD that is comparable with that of children with general ADHD, subsequent blinded assignment to 8 weeks of fluvoxamine treatment was not found to be statistically superior to placebo, based on the Pediatric Anxiety Rating Scale or Clinical Global Impressions-Improvement.

\section{Childhood mood disorders}

Affective disorders occur at elevated rates in ADHD, and the management of comorbid depressed or irritable/explosive in the context of ADHD represents a particularly difficult clinical challenge. One study to date has examined atomoxetine in adolescents with ADHD and comorbid major depressive disorder (MDD). ${ }^{52}$ Patients were treated for approximately 9 weeks with atomoxetine $(\leq 1.8 \mathrm{mg} / \mathrm{kg}$ per day) $(\mathrm{n}=72)$ or placebo $(n=70)$. While atomoxetine was effective in significantly reducing ADHD symptoms in this depressed sample, Children's Depression Rating Scale-Revised (CDRS-R) score improvement was not significantly different between groups (atomoxetine, $-14.8 \pm 13.3$; placebo, $-12.8 \pm 10.4$ ). Rates of treatment-emergent mania did not differ between groups (atomoxetine, 0.0\%; placebo, 1.5\%) nor was there spontaneously reported adverse events involving suicidal ideation or suicidal behavior in either group.

In an earlier study by Kratochvil et $\mathrm{al}^{53}$ patients with ADHD and concurrent symptoms of depression or anxiety were randomized to treatment with fluoxetine $(n=127)$ or placebo $(n=46)$ under double-blind conditions for 8 weeks, with concomitant atomoxetine during the last 5 weeks. Depressive symptom reductions according to the CDRS-R were not different between groups. Yet, interestingly, improvement in CDRS-R was significantly greater in subjects with the highest atomoxetine serum levels.

There are limited data to guide the clinician in the management of bipolar disorder (BD) and ADHD. Hah and Chang ${ }^{54}$ reported a consecutive case series on 7 patients with pediatric $\mathrm{BD}$ and $\mathrm{ADHD}$ who were treated with atomoxetine. The majority (6) of patients were treated concurrently with mood stabilizers. All but 1 patient demonstrated significant improvement in symptoms of ADHD. No patients had episodes of hypomania or mania during the treatment period.

\section{Tolerability}

\section{General tolerability}

Atomoxetine is generally well tolerated in healthy children and adolescents, with mild adverse effects. Based on data from 6 acute treatment clinical trials (6-9 weeks' duration) involving 280 younger children ages 6 to 7 years, and 860 older subjects, ages 8 to 12 years, younger children had significantly higher rates of upper abdominal pain, decreased appetite, vomiting, and somnolence (atomoxetine versus placebo [PBO]). Among older children, there were significantly higher rates of decreased appetite, somnolence, irritability, and fatigue observed for those taking atomoxetine versus PBO. ${ }^{19}$ In this review, a significant treatment-by-age-group interaction was observed for abdominal pain (younger: atomoxetine $=19 \%, \mathrm{PBO}=6 \%$; older: atomoxetine $=15 \%, \mathrm{PBO}=13 \% ; \mathrm{p}=0.044)$, and vomiting (younger: atomoxetine $=14 \%, \mathrm{PBO}=2 \%$; older: atomoxetine $=9 \%, \mathrm{PBO}=6 \% ; \mathrm{p}=0.053) .{ }^{19}$ No new or unexpected safety concerns have been reported over longer-term treatment. ${ }^{24}$

\section{Enhancing general tolerability; titration, and dosing}

Data on atomoxetine treatment and the emergence of adverse events has shown that the frequency of adverse events may depend on method of drug initiation. During initiation of therapy, patients rapidly titrating to $1.2 \mathrm{mg} / \mathrm{kg} / \mathrm{day}$ over 3 days, as a single daily dose, reported higher rates of spontaneous adverse events than patients on a twice-daily dosing with gradual titration over 3 weeks. ${ }^{55}$ Clinically, some children may tolerate a divided dose well during initiation of treatment, and then be able to switch over to a once-daily dosing schedule for maintenance.

\section{Atomoxetine and growth}

In a 5-year safety of treatment study, Spencer et $\mathrm{al}^{35}$ reported on the impact of atomoxetine on growth in a large sample of children and adolescent participants. Maximum decrement of weight loss was observed at 15 months $(-9.9 \%$ percentage points; $\mathrm{p}<0.001$ ); however by the 5 -year time point, subjects had slightly overshot their starting weight percentile. Similarly, maximum decrement from expected height was observed at 18 mos $(-6.6 \%$ percentage points; $\mathrm{p}<0.001)$. The impact of ADHD pharmacotherapy on growth is an area of ongoing research, including studies of stimulant class and non-stimulant medications, and the consideration of moderating impact of age. However, at present, continuous atomoxetine treatment does not appear to have significant effect on juvenile growth and final stature for most patients. ${ }^{35}$

\section{Atomoxetine and suicidality}

The following boxed warning has been placed (July, 2008) into the package insert for atomoxetine: "Atomoxetine increased the risk of suicidal ideation in short-term studies in 
children or adolescents with Attention-Deficit/Hyperactivity Disorder (ADHD). Pooled analyses of short-term (6-18 weeks) placebo-controlled trials of STRATTERA in children and adolescents (a total of 12 trials involving over 2200 patients, including 11 trials in ADHD and 1 trial in enuresis) have revealed a greater risk of suicidal ideation early during treatment in those receiving STRATTERA compared to placebo. The average risk of suicidal ideation in patients receiving STRATTERA was $0.4 \%$ (5/1357 patients), compared to none in placebo-treated patients (851 patients). No suicides occurred in these trials."

In a meta-analysis of 14 trials on suicide-related behavior in pediatric patients treated with study drug, placebo, or methylphenidate, no ADHD patients being treated with atomoxetine committed suicide. ${ }^{45}$ The frequency of suicidal ideation in patients taking atomoxetine was $0.37 \%$ vs $0 \%$ in a placebo group. Frequencies between atomoxetine and methylphenidate groups did not differ. ${ }^{45}$

In sum, there is no current evidence that atomoxetine causes suicide in youth. However, consistent with FDA recommendations, clinicians should consider the impact of psychiatric comorbidity, which may be associated with suicidal ideation and/or suicidal behavior. Clinicians should inquire about personal or family histories of mood disorders, as well as clarify whether suicidality has been present before starting atomoxetine. As part of monitoring, clinicians can then inquire about any (negative) changes in mood during treatment, eg, depression, agitation, or worsening of frustration tolerance (in contrast to effective ADHD treatment in which parents will often comment on improved mood, noting that the child is less reactive, irritable or easily frustrated).

\section{Atomoxetine and aggression/psychosis}

In a meta-analysis of aggression/hostility-related events from 14 trials of atomoxetine, aggression/hostility-related events occurred in less than $2 \%$ of patients and were more frequent in pediatric patients treated with atomoxetine versus placebo (risk ratio of 1.33; not statistically significant). The risk of aggression/hostility events was similar in patients treated with atomoxetine or methylphenidate. ${ }^{56}$ In a pooled analysis of multiple short-term, placebo-controlled studies, such symptoms occurred in about $0.2 \%$ (4 patients with reactions out of 1939 exposed to atomoxetine for several weeks at usual doses) of atomoxetine-treated patients compared to 0 out of 1056 placebo-treated patients (Lilly, Product Information, July 2008).

As per the current FDA medication guide, while rare, treatment emergent psychotic or manic symptoms may occur. Therefore, the same principles as described above apply; clinicians should inquire about personal or family histories of mood disorders and psychosis prior to initiation of atomoxetine. If mood changes occur, inquiry about additional symptoms such as pressured speech, and decreased need for sleep may assist in identifying irritability associated with mania/bipolar disorder, from irritability, which may be more consistent with fluctuating levels of oppositionality.

\section{Atomoxetine and hepatic injury}

There have been rare reports of hepatic injury associated with atomoxetine. In an investigation of case reports identified by a computerized search that contained potential hepatic events, of the 7962 pediatric and adult patients treated with atomoxetine in clinical trials, 41 were identified as requiring further analysis. Of those 41 cases, none progressed to liver failure, and most of these events were mild increases in aminotransferase (ALT) and aspartate aminotrasferase (AST) levels. ${ }^{45}$ During the 4 years after the market launch of atomoxetine, 351 cases of liver injury were related to the drug treatment for ADHD. Of those 351 cases, 69 had explanations unrelated to the use of the drug, 146 presented insufficient information to assess the cause, 133 contained confounding factors and were labeled as possibly related to drug use, and the remaining 3 cases reported liver injury probably related to atomoxetine use. ${ }^{45}$ The etiology of drug-induced liver injury with atomoxetine may be metabolic idiosyncrasy or induced autoimmune hepatitis. ${ }^{57}$

Given the rare nature of these reports, it is not currently recommended for clinicians to do routine monitoring of liver function tests during treatment, however, families should inform clinicians if they find evidence of liver problems; itching, right upper belly pain, dark urine, yellow skin or eyes, or unexplained flu-like symptoms (Lilly, Product Information, July 2008).

\section{Atomoxetine and the cardiovascular system}

There is no current evidence that treatment with therapeutic doses of ADHD pharmacotherapies in healthy children causes serious cardiovascular effects or sudden death. ${ }^{58}$ However, sudden death has been reported in association with atomoxetine treatment at usual doses in children and adolescents with structural cardiac abnormalities or other serious heart problems. Although some serious heart problems alone carry an increased risk of sudden death, atomoxetine generally should not be used in children or adolescents with known serious structural cardiac abnormalities, cardiomyopathy, and serious heart rhythm (Lilly, Production Information, 2008). 
Children who are being considered for treatment with atomoxetine should have a careful clinical history (including assessment for a family history of early sudden death) and physical exam to assess for the presence of cardiac disease, as well as inquiring about possible cardiac symptoms including chest pain and syncope. Electrocardiogram (ECG) is not a mandatory component of cardiovascular assessment and monitoring before and during ADHD pharmacotherapy. ${ }^{58,59}$

It is well documented that atomoxetine may increase heart rate in both younger (atomoxetine, 8.7 bpm [12.7]; PBO, 1.0 (13.7); $\mathrm{p}=0.001$ ) and older (atomoxetine, $6.8 \mathrm{bpm}$ [11.7]; PBO, 0.6 [11.3]; $\mathrm{p}<0.001)$ children. A statistically significant treatment-group difference in systolic blood pressure (atomoxetine, 2.1 [9.8] mmHg; PBO, 0.3 [8.1] mmHg; $\mathrm{p}=0.034$ ) and diastolic blood pressure (atomoxetine, 2.9 [8.2] $\mathrm{mmHg}$; PBO, 0.6 [8.0] mmHg; $\mathrm{p}=0.002$ ) has been observed for older children, but not for younger children. ${ }^{19}$

According to the current FDA medication guide, pulse and blood pressure should be measured at baseline, and periodically while on therapy. Such vigilance may identify certain children at heightened risk. For example, based upon pooled safety data, significantly greater increases in mean pulse rate at endpoint $(+3.9 \mathrm{bpm})$ and in mean diastolic blood pressure (DBP) at endpoint $(+1.6 \mathrm{mmHg})$ have been observed in PMs, as compared to EMs. ${ }^{13}$ In addition, outliers ( $2.5 \%$ in pediatric placebo controlled trials) have been identified, with HR increases $>25 \mathrm{bpm} ; 1.1 \%$ had increases in HR of this magnitude on more than one occasion (Lilly, Product Information, July 2008). Significant deviations from baseline vital signs and/or blood pressure in the pre-hypertension or hypertension range can be reviewed with the child's primary care clinician and specialists in pediatric hypertension.

\section{Atomoxetine and CNS toxicity}

The rate of seizures as an adverse event with atomoxetine use has been estimated at between 0.1 and $0.2 \% .{ }^{60}$ Post-market reports of seizure events were deemed as having no clear contributing or confounding factors, and the rate of report was within the normal population occurrences. ${ }^{60}$

\section{Atomoxetine and overdose}

Several studies have examined what happens when a child or adolescent is exposed to an overdose of atomoxetine, based upon poison center reports. ${ }^{61-64}$ Doses to $6.25 \mathrm{mg} / \mathrm{kg},{ }^{61}$ to $249 \pm 326 \mathrm{mg},{ }^{62}$ and to $1200 \mathrm{mg}^{63}$ have been reported. In some reports, adverse drug reactions did not correlate with atomoxetine dose. ${ }^{61}$ In others, higher rates of serious outcome were found with greater maximum dose; $>2.8 \mathrm{mg} / \mathrm{kg}$ or $>200 \mathrm{mg}$ or $>4$ tablets. ${ }^{64}$ No major outcomes or fatalities have been reported. ${ }^{62,63}$

However, exposures have caused GI upset, lethargy ${ }^{61-63}$ and seizures in one child, ${ }^{62}$ and seizures in one adolescent female who ingested $2840 \mathrm{mg}$ of atomoxetine in a suicide attempt; serum atomoxetine level of $1995 \mathrm{ng} / \mathrm{mL} .{ }^{65}$ Cardiovascular sequela has included sinus tachycardia, and increased blood pressure. ${ }^{61-63}$ Mood adverse effects include agitation; ${ }^{61}$ in one study, $17 \%$ had acute agitation and were treated with benzodiazepines. ${ }^{63}$ Despite this apparent safety profile, clinicians should discuss with the patient and family members the importance of taking the atomoxetine doses as prescribed and appropriate monitoring of medications in the home.

\section{Drug-drug interactions}

Based upon preclinical data, atomoxetine is metabolized by CYP2D6, but does not induce or inhibit it. ${ }^{13}$ However, CYP2D6 inhibitors may reduce atomoxetine clearance; fluoxetine, paroxetine, and quinidine, all drugs that inhibit CYP2D6, cause higher peak plasma concentrations and slower elimination. ${ }^{9}$ Thus, these CYP2D6 inhibitors may create an iatrogenic virtual PM phenotype in patients with an EM genotype. ${ }^{13}$

Atomoxetine should not be used within 2 weeks after discontinuing MAOI or other drugs that affect brain monoamine concentrations. Atomoxetine should be prescribed with caution if a patient is taking asthma (albuterol or other beta2 agonists), or other medications which could potentiate pressor effects. In addition, there are a few case reports of neurological adverse events when atomoxetine is taken with other drugs; neck-facial twitches/tics with concurrent citalopram, ${ }^{66}$ venlafaxine, ${ }^{67}$ involuntary movements with a stimulant. ${ }^{67}$ In these cases, symptoms resolved after the discontinuation of atomoxetine and other medications.

\section{Summary}

Atomoxetine is indicated for both acute and maintenance/ extended treatment of pediatric ADHD. There is extensive literature on atomoxetine, documenting its pharmacodynamic and pharmacokinetic properties, as well as its short- and longer-term efficacy, the moderating effect of comorbid disorders, and analyses of short- and long-term safety and tolerability. Overall, more children and adolescents have been studied in acute and long-term prospective studies with atomoxetine than with any other pediatric psychotropic in history. To date, over 4000 children have participated in 
clinical trials of atomoxetine, including 7 pediatric trials, of which 6 were a randomized, double-blind, placebo-controlled design. ${ }^{19,68}$

Clinicians and families should be well informed in regards to this evidence base, including the potential for a different profile of clinical response, as compared to stimulant class medications. Atomoxetine's full effects may accrue over months not weeks, and thus patience is necessary in prescribing and administering this medication. We can now point to controlled data demonstrating a near $50 \%$ atomoxetine response in children who recently failed a stimulant trial.

While atomoxetine has an overall effect size lower than the first line stimulant class medications in short-term studies, it may be a better drug for an individual child. Given positive preliminary data in some of the more challenging comorbid conditions that occur in children with ADHD (ODD, tics, anxiety and mood disorders, PDD), atomoxetine's role in these more complex patients may continue to emerge.

Finally, the FDA has recommended the development of medication guides, now available for all ADHD pharmacotherapeutic agents, including atomoxetine. Clinicians and families should be familiar with the latest recommendations and consensus, particularly as they apply to areas of cardiovascular safety and the monitoring of mood/behavioral changes and suicidality. The medication guide for atomoxetine can be found at http://www. fda.gov/cder/Offices/MG/atomoxetineMG/pdf. Consistent with current clinical consensus that ADHD is a chronic disorder, with impairment into adulthood, further research is warranted, to examine the efficacy and safety of atomoxetine over extended periods of time.

\section{Disclosures}

Dr. Daniel Geller MD receives(ed) lifetime

- Research support: Eli Lilly and Co., Forest Laboratories, Glaxo-SmithKline, Boehringer Ingelheim Pharmaceuticals, Inc.

- Speaker Honoraria: Alza, Bristol-Myers-Squibb, Eli Lilly, Forest Laboratories, Glaxo-SmithKline, Novartis, Pfizer, Shire, Wyeth.

- Medical Advisory Boards/Consulting: Eli Lilly, Solvay, Pfizer, Lundbeck and Glaxo-SmithKline.

- Private Foundations: Obsessive Compulsive Foundation, Tourette Syndrome Association, Wallace Foundation, McIngvale Family Foundation.

- NIH: National Institute of Mental Health, National Institute of Neurological Disorders and Stroke

Dr. Daniel Geller MD receives/d inlast 12 months (to November 2008).
- Research support: Eli Lilly.

- Speaker Honoraria: Eli Lilly.

- Medical Advisory Boards/Consulting: Eli Lilly.

- Private Foundations: McIngvale Family Foundation.

- NIH: National Institute of Neurological Disorders and Stroke, National Institute of Mental Health.

\section{References}

1. Visser SN, Lesesne CA, Perou R. National estimates and factors associated with medication treatment for childhood attention-deficit/ hyperactivity disorder. Pediatrics. 2007;119 Suppl 1:S99-S106.

2. Pliszka S. Practice parameter for the assessment and treatment of children and adolescents with attention-deficit/hyperactivity disorder. J Am Acad Child Adolesc Psychiatry. 2007;46(7):894-921.

3. Brown RT, Amler RW, Freeman WS, et al. Treatment of attentiondeficit/hyperactivity disorder: overview of the evidence. Pediatrics. 2005;115(6): e749-e 757.

4. Wong DT, Threlkeld PG, Best KL, Bymaster FP. A new inhibitor of norepinephrine uptake devoid of affinity for receptors in rat brain. J Pharmacol Exp Ther. 1982;222(1):61-65.

5. Bolden-Watson C, Richelson E. Blockade by newly-developed antidepressants of biogenic amine uptake into rat brain synaptosomes. Life Sci. 1993;52(12):1023-1029.

6. Bymaster FP, Katner JS, Nelson DL, et al. Atomoxetine increases extracellular levels of norepinephrine and dopamine in prefrontal cortex of rat: a potential mechanism for efficacy in attention deficit/hyperactivity disorder. Neuropsychopharmacology. 2002;27(5):699-711.

7. Swanson CJ, Perry KW, Koch-Krueger S, Katner J, Svensson KA, Bymaster FP. Effect of the attention deficit/hyperactivity disorder drug atomoxetine on extracellular concentrations of norepinephrine and dopamine in several brain regions of the rat. Neuropharmacology. 2006;50(6):755-760.

8. Witcher JW, Long A, Smith B, et al. Atomoxetine pharmacokinetics in children and adolescents with attention deficit hyperactivity disorder. J Child Adolesc Psychopharmacol. 2003;13(1):53-63.

9. Sauer JM, Ring BJ, Witcher JW. Clinical pharmacokinetics of atomoxetine. Clin Pharmacokinet. 2005;44(6):571-590.

10. Corman SL, Fedutes BA, Culley CM. Atomoxetine: the first nonstimulant for the management of attention-deficit/hyperactivity disorder. Am J Health Syst Pharm. 2004;61(22):2391-2399.

11. Ring BJ, Gillespie JS, Eckstein JA, Wrighton SA. Identification of the human cytochromes P450 responsible for atomoxetine metabolism. Drug Metab Dispos. 2002;30(3):319-323.

12. Sauer JM, Ponsler GD, Mattiuz EL, et al. Disposition and metabolic fate of atomoxetine hydrochloride: The role of CYP2D6 in human disposition and metabolism. Drug Metab Dispos. 2003;31:98-107.

13. Michelson D, Adler L, Amsterdam J, et al. Addition of atomoxetine for depression incompletely responsive to sertraline: a randomized, doubleblind, placebo-controlled study. J Clin Psychiatry. 2007;68(4):582-587.

14. Chalon SA, Desager JP, Desante KA, et al. Effect of hepatic impairment on the pharmacokinetics of atomoxetine and its metabolites. Clin Pharmacol Ther. 2003;73(3):178-191.

15. Spencer T, Biederman J, Heiligenstein J, et al. An Open-Label, Dose-Ranging Study of Atomoxetine in Children with Attention Deficit Hyperactivity Disorder. J Child Adolesc Psychopharmacol. 2001;11(3):251-265.

16. Michelson D, Faries D, Wernicke J, et al. Atomoxetine in the treatment of children and adolescents with attention-deficit/hyperactivity disorder: A randomized, placebo-controlled, dose-response study. Pediatrics. 2001;108(5).

17. Weiss M, Tannock R, Kratochvil C, et al. A randomized, placebocontrolled study of once-daily atomoxetine in the school setting in children with ADHD. J Am Acad Child Adolesc Psychiatry. 2005;44(7): 647-655. 
18. Cheng JY, Chen RY, Ko JS, Ng EM. Efficacy and safety of atomoxetine for attention-deficit/hyperactivity disorder in children and adolescentsmeta-analysis and meta-regression analysis. Psychopharmacology (Berl). 2007;194(2):197-209.

19. Kratochvil CJ, Milton DR, Vaughan BS, Greenhill LL. Acute atomoxetine treatment of younger and older children with ADHD: A metaanalysis of tolerability and efficacy. Child Adolesc Psychiatry Ment Health. 2008;2(1):25.

20. Faraone SV, Biederman J, Spencer TJ, Aleardi M. Comparing the efficacy of medications for ADHD using meta-analysis. Med Gen Med. 2006;8(4):4

21. Kemner JE, Starr HL, Ciccone PE, Hooper-Wood CG, Crockett RS. Outcomes of OROS methylphenidate compared with atomoxetine in children with ADHD: a multicenter, randomized prospective study. Adv Ther. 2005;22(5):498-512.

22. Wigal SB, McGough JJ, McCracken JT, et al. A laboratory school comparison of mixed amphetamine salts extended release (Adderall XR) and atomoxetine (Strattera) in school-aged children with attention deficit/hyperactivity disorder. J Atten Disord. 2005;9(1):275-289.

23. Kratochvil CJ, Heiligenstein JH, Dittman R, et al. Atomoxetine and methylphenidate treatment in children with ADHD: A prospective, randomized, open-label trial. J Am Acad Child Adolesc Psychiatry. 2002;41(7):776-784.

24. Wilens TE, Newcorn JH, Kratochvil CJ, et al. Long-term atomoxetine treatment in adolescents with attention-deficit/hyperactivity disorder. J Pediatr. 2006;149(1):112-119.

25. Michelson D, Allen AJ, Busner J, et al. Once-Daily Atomoxetine Treatment for Children and Adolescents with Attention Deficit Hyperactivity Disorder: A Randomized, Placebo-Controlled Study. Am J Psychiatry. 2002;159(11):1896-1901.

26. Kelsey DK, Sumner CR, Casat CD, et al. Once-daily atomoxetine treatment for children with attention-deficit/hyperactivity disorder, including an assessment of evening and morning behavior: a doubleblind, placebo-controlled trial. Pediatrics. 2004;114(1):e1-e8.

27. Newcorn JH, Kratochvil CJ, Allen AJ, et al. Atomoxetine and osmotically released methylphenidate for the treatment of attention deficit hyperactivity disorder: acute comparison and differential response. Am J Psychiatry. 2008;165(6):721-730.

28. Quintana H, Cherlin EA, Duesenberg DA, et al. Transition from methylphenidate or amphetamine to atomoxetine in children and adolescents with attention-deficit/hyperactivity disorder - a preliminary tolerability and efficacy study. Clin Ther. 2007;29(6):1168-1177.

29. Hammerness P, Mick E, Doyle R, et al. Atomoxetine in children with attention deficit hyperactivity disorder (ADHD) with prior poor response to stimulant therapy: a prospective open label study. Eur Child Adolesc Psychiatry. 2009; in revision.

30. Kratochvil CJ, Michelson D, Newcorn JH, et al. High-dose atomoxetine treatment of ADHD in youths with limited response to standard doses. J Am Acad Child Adolesc Psychiatry. 2007;46(9):1128-1137.

31. Safer DJ, Zito JM, DosReis S. Concomitant psychotropic medication for youths. Am J Psychiatry. 2003;160(3):438-449.

32. Carlson GA, Dunn D, Kelsey D, et al. A pilot study for augmenting atomoxetine with methylphenidate: safety of concomitant therapy in children with attention-deficit/hyperactivity disorder. Child Adolesc Psychiatry Ment Health. 2007;1(1):10.

33. Wilens T, Hammerness P, Utzinger L, et al. An open study of adjunct OROS-methylphenidate in children who are atomoxetine partial responders: I. effectiveness. J Child Adolesc Psychopharmacol. In press.

34. Kratochvil C, Wilens T, Greenhill L, et al. Effects of long-term atomoxetine treatment for young children with Attention-deficit/ hyperactive disorder. J Am Acad Child Adolesc Psychiatry. 2006;45(8): 919-927.

35. Spencer TJ, Kratochvil CJ, Sangal RB, et al. Effects of atomoxetine on growth in children with attention-deficit/hyperactivity disorder following up to five years of treatment. $J$ Child Adolesc Psychopharmacol. 2007;17(5):689-699.
36. Bakken RJ, Paczkowski M, Kramer HP, et al. Effects of atomoxetine on attention-deficit/hyperactivity disorder in clinical pediatric treatment settings: a naturalistic study. Curr Med Res Opin. 2008;24(2): 449-460.

37. Michelson D, Buitelaar JK, Danckaerts M, et al. Relapse prevention in pediatric patients with ADHD treated with atomoxetine: a randomized, double-blind, placebo-controlled study. J Am Acad Child Adolesc Psychiatry. 2004;43(7):896-904.

38. Michelson D. Treatment of ADHD: beyond stimulants. Presented at the 15th European Neuropsychopharmacology Congress, Barcelona, Spain. Eur Neuropsychopharmacol. 2002;12(Suppl 3):S77-S457.

39. Buitelaar JK, Michelson D, Danckaerts M, et al. A randomized, doubleblind study of continuation treatment for attention-deficit/hyperactivity disorder after 1 year. Biol Psychiatry. 2007;61(5):694-699.

40. Biederman J, Spencer TJ, Newcorn JH, et al. Effect of comorbid symptoms of oppositional defiant disorder on responses to atomoxetine in children with ADHD: a meta-analysis of controlled clinical trial data. Psychopharmacology (Berl). 2007;190(1):31-41.

41. Newcorn JH, Spencer TJ, Biederman J, Milton DR, Michelson D. Atomoxetine Treatment in Children and Adolescents with AttentionDeficit/Hyperactivity Disorder and Comorbid Oppositional Defiant Disorder. J Am Acad Child Adolesc Psychiatry. 2005;44(3):240-248.

42. Hazell P, Zhang S, Wolanczyk T, et al. Comorbid oppositional defiant disorder and the risk of relapse during 9 months of atomoxetine treatment for attention-deficit/hyperactivity disorder. Eur Child Adolesc Psychiatry. 2006;15(2):105-110.

43. Spencer T, Heiligenstein JH, Biederman J, et al. Results from 2 proof-of-concept, placebo-controlled studies of atomoxetine in children with attention-deficit/hyperactivity disorder. J Clin Psychiatry. 2002;63(12):1140-1147.

44. Kaplan S, Heiligenstein J, West S, et al. Efficacy and safety of atomoxetine in childhood attention-deficit/hyperactivity disorder with comorbid oppositional defiant disorder. J Atten Disord. 2004;8(2):45-52.

45. Bangs ME, Hazell P, Danckaerts M, et al. Atomoxetine for the treatment of attention-deficit/hyperactivity disorder and oppositional defiant disorder. Pediatrics. 2008;121(2):e314-e320.

46. Arnold P, Sicard T, Burroughs E, Richter M, Kennedy J. Glutamate transporter gene SLC1A1 associated with obsessive-oompulsive disorder. Arch Gen Psychiatry. 2006;63(7):717-720.

47. Troost PW, Steenhuis MP, Tuynman-Qua HG, et al. Atomoxetine for attention-deficit/hyperactivity disorder symptoms in children with pervasive developmental disorders: a pilot study. $J$ Child Adolesc Psychopharmacol. 2006;16(5):611-619.

48. Posey D, Erickson C, Stigler KA, McDougle C. The use of selective serotonin reuptake inhibitors in autism and related disorders. $J$ Child Adolesc Psychopharmacol. 2006;16(1-2):181-186.

49. Allen AJ, Kurlan R, Gilbert DL, et al. Atomoxetine treatment in children and adolescents with ADHD and comorbid tic disorders. Neurology. 2005;65:1941-1949.

50. Geller D, Donnelly C, Lopez F, et al. Atomoxetine treatment for pediatric patients with ADHD and comorbid anxiety. J Am Acad Child Adolesc Psychiatry. 2007;46(9):11.

51. Abikoff H, McGough J, Vitiello B, et al. Sequential pharmacotherapy for children with comorbid Attention-Deficit/Hyperactivity and anxiety disorders. J Am Acad Child Adolesc Psychiatry. 2005;44(5): $418-427$.

52. Bangs ME, Emslie GJ, Spencer TJ, et al. Efficacy and safety of atomoxetine in adolescents with attention-deficit/hyperactivity disorder and major depression. J Child Adolesc Psychopharmacol. 2007;17(4):407-420.

53. Kratochvil CJ, Newcorn JH, Arnold LE, et al. Atomoxetine alone or combined with fluoxetine for treating ADHD with comorbid depressive or anxiety symptoms. $J$ Am Acad Child Adolesc Psychiatry. 2005;44(9):915-924.

54. Hah M, Chang K. Atomoxetine for the treatment of attention-deficit/ hyperactivity disorder in children and adolescents with bipolar disorders. J Child Adolesc Psychopharmacol. 2005;15(6):996-1004. 
55. Greenhill LL, Newcorn JH, Gao H, Feldman PD. Effect of two different methods of initiating atomoxetine on the adverse event profile of atomoxetine. J Am Acad Child Adolesc Psychiatry. 2007;46(5):566-572.

56. Polzer J, Bangs ME, Zhang S, et al. Meta-analysis of aggression or hostility events in randomized, controlled clinical trials of atomoxetine for ADHD. Biol Psychiatry. 2007;61(5):713-719.

57. Lim JR, Faught PR, Chalasani NP, Molleston JP. Severe liver injury after initiating therapy with atomoxetine in two children. J Pediatr. 2006;148(6):831-834.

58. Perrin JM, Friedman RA, Knilans TK. Cardiovascular monitoring and stimulant drugs for attention-deficit/hyperactivity disorder. Pediatrics. 2008;122(2):451-453.

59. Association A. American Academy of Pediatrics/American Heart Association clarification of statement on cardiovascular evaluation and monitoring of children and adolscents with heart disease receiving medications for ADHD. May 16, 2008.

60. Wernicke JF, Holdridge KC, Jin L, et al. Seizure risk in patients with attention-deficit-hyperactivity disorder treated with atomoxetine. Dev Med Child Neurol. 2007;49(7):498-502.

61. Stojanovski SD, Robinson RF, Baker SD, Casavant MJ, Hayes JR, Nahata MC. Children and adolescent exposures to atomoxetine hydrochloride reported to a poison control center. Clin Toxicol (Phila). 2006;44(3):243-247.
62. Spiller HA, Lintner CP, Winter ML. Atomoxetine ingestions in children: a report from poison centers. Ann Pharmacother. 2005;39(6): 1045-1048.

63. Lovecchio F, Kashani J. Isolated atomoxetine (Strattera) ingestions commonly result in toxicity. J Emerg Med. 2006;31(3):267-268.

64. Forrester MB. Adult atomoxetine ingestions reported to Texas Poison Control Centers, 2003-2005. Ann Pharmacother. 2006;40(12):2136-2141.

65. Kashani J, Ruha AM. Isolated atomoxetine overdose resulting in seizure. J Emerg Med. 2007;32(2):175-178.

66. Párraga H, Párraga M, Harris D. Tic exacerbation and precipitation during atomoxetine treatment in two children with attention-deficit hyperactivity disorder. Int J Psychiatry Med. 2007;37(4):415-424.

67. Bond GR, Garro AC, Gilbert DL. Dyskinesias associated with atomoxetine in combination with other psychoactive drugs. Clin Toxicol (Phila). 2007;45(2):182-185.

68. Allen AJ, Michelson D. Drug development process for a product with a primary pediatric indication. J Clin Psychiatry. 2002;(63 Suppl 12):44 49. 